\title{
Hemolysis Following Coil Embolization of a Patent Ductus Arteriosus
}

\author{
David Shim, MD, Daniel S. Wechsler, MD, PhD, Thomas R. Lloyd, MD, and \\ Robert H. Beekman III, MD
}

\begin{abstract}
We describe the development of hemolys/s from moderate residual shunting across a patent ductus arteriosus following coil embolization. The fall in hemoglobin levels from 11.6 to $6.0 \mathrm{gm} / \mathrm{dl}$ necessitated a second coil procedure which resulted in complete closure of the residual shunting and resolution of hemolysis. Therefore, appearance of anemia following coil embolization of patent ductus arteriosus should be monitored closely; however, repeat coil embolization with elimination of residual shunt will lead to prompt recovery of normal hemoglobin levels. (c) 1996 Wiloy-Liss, Inc.
\end{abstract}

Key words: patent ductus arteriosus, hemolysis, coll embolization

\section{INTRODUCTION}

Coil embolization of patent ductus arteriosus (PDA) has become the treatment of choice for closure of patent ductus arteriosus in some institutions [1,2]. Complications have been few and there are no published reports of hemolysis after ductus coil embolization. We report a case of intravascular hemolysis after coil embolization of PDA.

\section{CASE REPORT}

A heart murmur was noted in a 4-month-old infant during evaluation for bronchiolitis and the patient was referred for cardiac evaluation. A continuous murmur consistent with PDA was present, but no clinical evidence of congestive heart failure was found. Echocardiography confirmed the presence of a restrictive PDA (62-80 $\mathrm{mm} \mathrm{Hg}$ pressure gradient between the aorta and pulmonary artery), with a dilated left atrium and ventricle secondary to volume overload. Examinations at 8 and 14 months of age continued to suggest PDA without congestive heart failure. Elective coil embolization of the PDA was scheduled at 16 months of age. Prior to the procedure, the child's hemoglobin (Hgb) was $11.6 \mathrm{~g} / \mathrm{dl}$. Cardiac catheterization and coil embolization was performed as was routine at our institution [1]. The minimum ductal diameter was found to be $2.8 \mathrm{~mm}$, with an angiographically large [1] left to right shunt (Fig. 1). A 0.038 in. $\times 8 \mathrm{~cm} \times 8 \mathrm{~mm}$ Gianturco steel embolization coil (Cook Inc., Bloomington, IN) was implanted across the ductus, and a repeat aortogram revealed a moderate persistent shunt 10 minutes after placement. A second 0.038 in. $x 5 \mathrm{~cm} \times 5 \mathrm{~mm}$ coil was implanted within the first coil, and a repeat aortogram revealed a small residual shunt (Fig. 1). Because such residual shunts typically decrease or resolve with time [3], and because placement of additional coils might dislodge and possibly embolize the first two coils, no further coils were implanted. The patient tolerated the procedure well and was discharged 6 $\mathrm{h}$ after leaving the catheterization laboratory.

On the evening of the first post-procedure day, the patient's urine appeared dark, although she was afebrile and otherwise asymptomatic. A urinalysis performed by her pediatrician the following morning revealed hemoglobinuria without red blood cells. Complete blood count revealed a decrease in $\mathrm{Hgb}$ to $10.2 \mathrm{~g} / \mathrm{dl}$ and microcytes were seen on peripheral blood smear. Blood chemistries performed on the third day were remarkable for markedly elevated lactate dehydrogenase $(5,240 \mathrm{IU} / \mathrm{L}$; normal $300-650)$ and total serum bilirubin $(1.8 \mathrm{mg} / \mathrm{dl}$; normal $0.1-1.0$ ). Serial laboratory studies over the following week revealed continued decrease in $\mathrm{Hgb}$ and increase in reticulocyte count (Fig. 2); therefore, referral was made to Pediatric Hematology. On the eighth post-procedure day, the reticulocyte count was $11 \%$ and peripheral blood smear was remarkable for the presence of nucleated red blood cells and evidence of hemolysis. Serum

From the Department of Pediatrics and Communicable Diseases, Division of Pediatric Cardiology, and Division of Pediatric Hematology-Oncology, C.S. Mott Children's Hospital, The University of Michigan, Ann Arbor, Michigan.

Received March 25, 1996; revision accepted June 6, 1996.

Address reprint requests to David Shim, M.D., Division of Pediatric Cardiology, Children's Hospital Medical Center, 3333 Burnet Avenue, Cincinnati, OH 45229. 

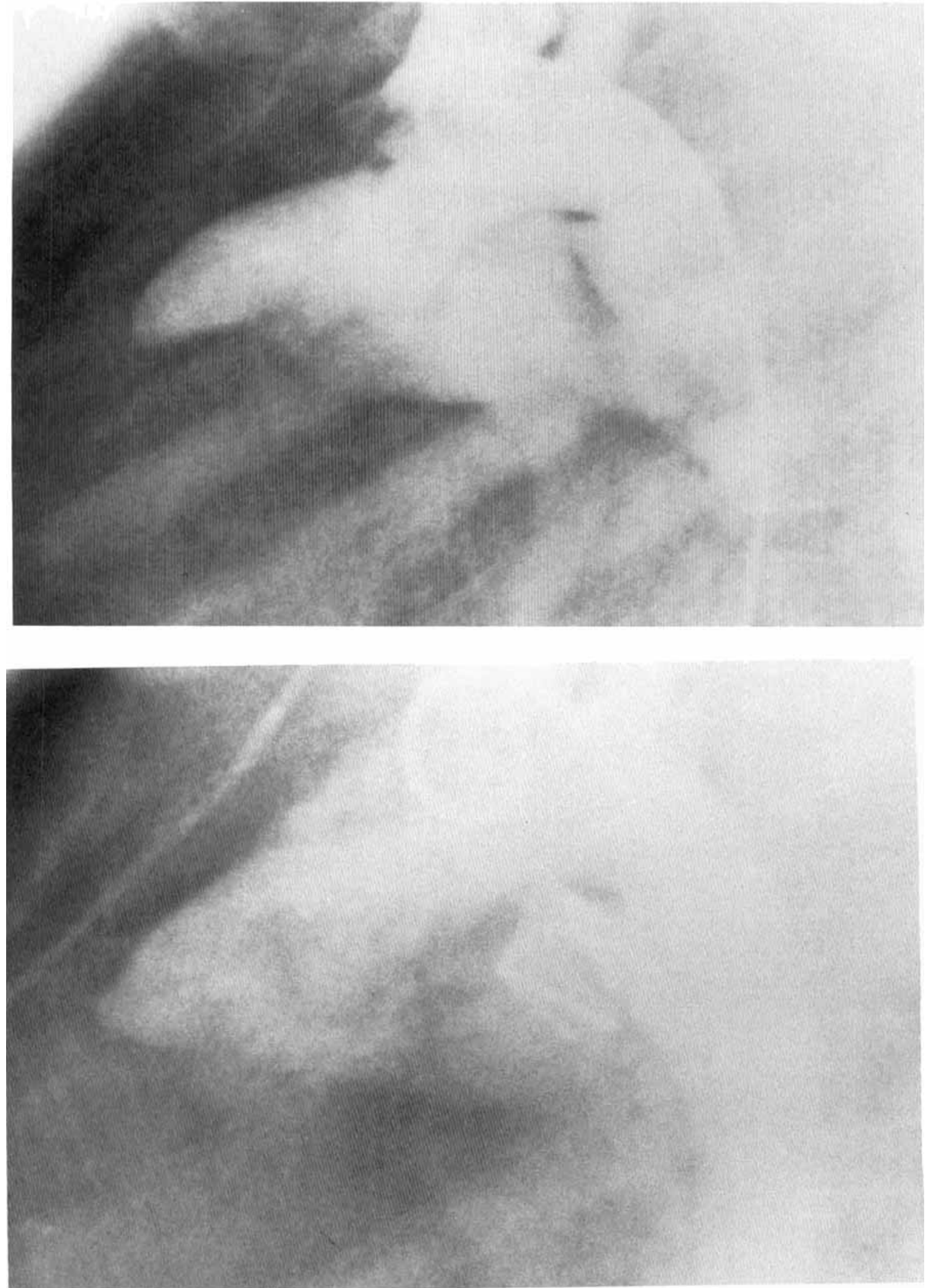

Fig. $1 A$ and $B$. 


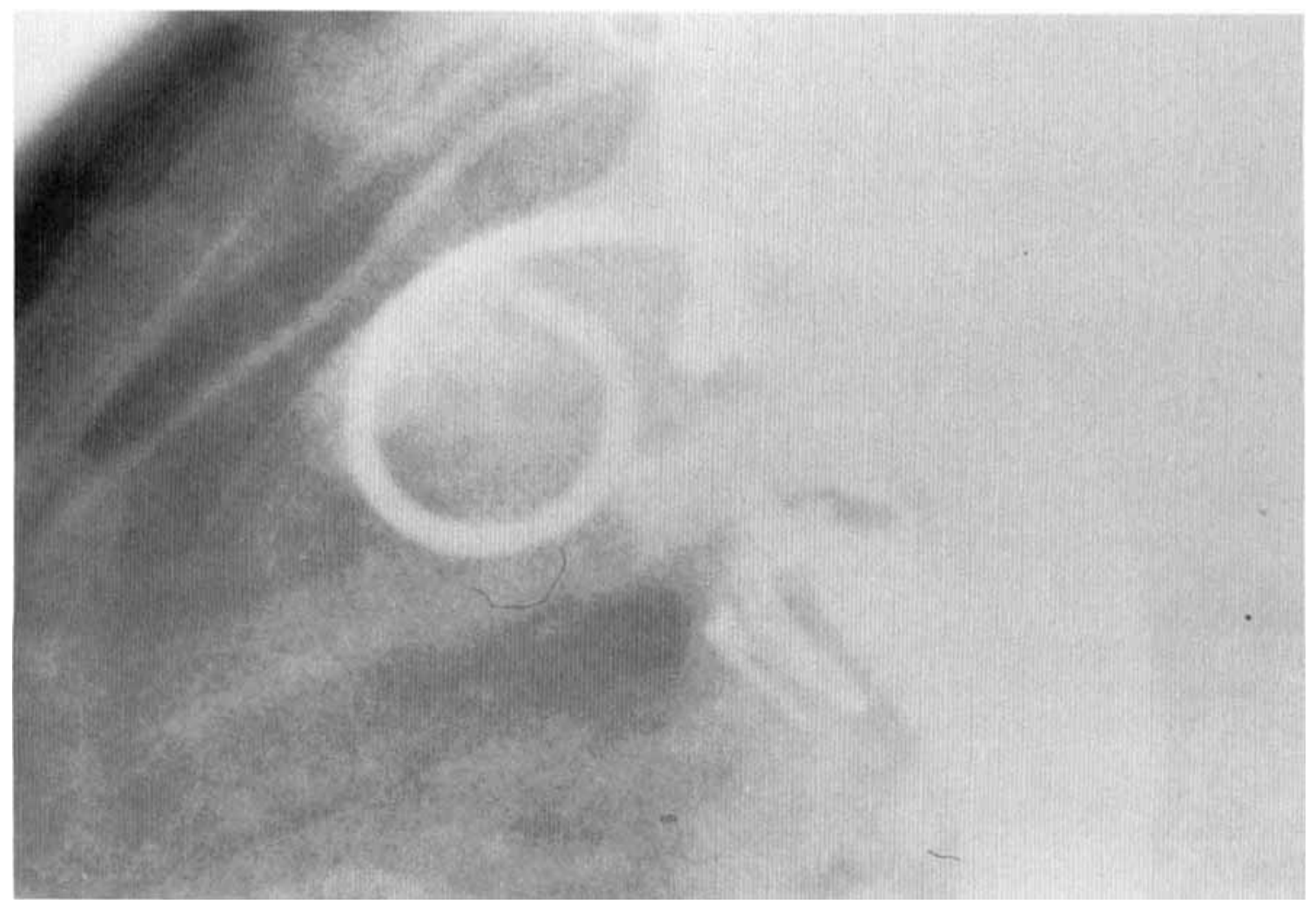

Fig. 1. A: Initial lateral aortogram revealing a large left-to-right shunt through a patent ductus arteriosus. B: After placement of 2 Gianturco coils, a small residual shunt is seen. Note the large

free hemoglobin was found to be elevated $(38.3 \mathrm{mg} / \mathrm{dl}$; normal 1-8), serum haptoglobin was markedly reduced ( $<6 \mathrm{mg} / \mathrm{dl}$; normal 22-239), and methemalbumin was detected $(0.14 \mathrm{~g} / \mathrm{dl}$; normal undetectable), all consistent with ongoing red cell breakdown. Urinalysis continued to reveal hemoglobinuria despite the urine appearing grossly clear. The platelet count was normal, and direct and indirect Coombs' tests were negative. Echocardiography revealed significant residual shunting across the PDA.

When the hemoglobin had dropped to $6.0 \mathrm{~g} / \mathrm{dl}$ on the ninth post-procedure day, the patient underwent a second coil embolization procedure, in which a 0.038 in. $\times 5$ $\mathrm{cm} \times 5 \mathrm{~mm}$ coil, a $0.038 \mathrm{in} . \times 4 \mathrm{~cm} \times 3 \mathrm{~mm}$ coil, and a 0.035 in. $\times 4 \mathrm{~cm} \times 3 \mathrm{~mm}$ coil were placed. Trace residual shunting was noted at repeat aortogram (Fig. 1), which was still evident on echocardiogram the following morning. The initial increase in the Hgb noted after this procedure (Fig. 2) may relate partially to dehydration, however the patient's hemolysis resolved with a steady increase in the patient's Hgb with a concomitant decrease in the reticulocyte count and lactate dehydrogenase over the following 4 weeks. She received no supplemental iron therapy. One month following the repeat coil em- coil loops in the lumen of the pulmonary artery. C: At a repeat coil procedure, 3 additional coils are implanted into the ductus with trace residual shunt noted on the final aortogram.

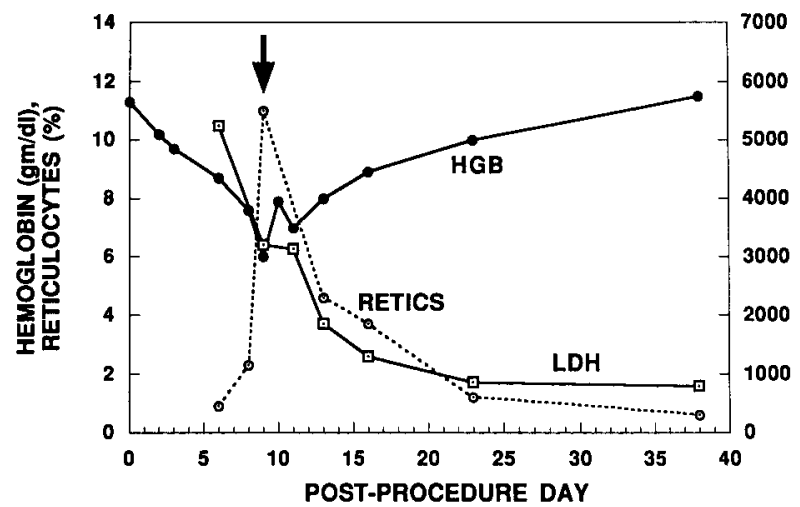

Fig. 2. Graph revealing decrease in hemoglobin (HGB) level and increase in reticulocyte count (RETICS) following the initial coil embolization procedure (day 0 ) and then recovery following a repeat coil procedure (arrow). There is also marked elevation of lactate dehydrogenase (LDH) initially on day 6 with steady decline following resolution of significant ductal shunting.

bolization procedure, the $\mathrm{Hgb}$ was $11.5 \mathrm{gm} / \mathrm{dl}$, reticulocyte count was $0.6 \%$, and the lactate dehydrogenase was $796 \mathrm{IU} / \mathrm{L}$. Echocardiography revealed no residual ductal shunting. 


\section{DISCUSSION}

Percutaneous coil occlusion of the patent ductus arteriosus has become the treatment of choice in many institutions with few complications [2]. Hemolysis following transcatheter occlusion has been previously described after implantation of a Rashkind PDA occlusion device $[4,5]$, but this phenomenon has not been reported after PDA occlusion with Gianturco coils. The patient described had clear evidence of ongoing hemolysis with a vigorous erythropoietic response. The development of anemia correlated with the presence of significant residual shunt and began to resolve after marked reduction of the residual shunt following the second coil embolization procedure. Presumably, red blood cells were traumatized due to the high velocity jet of residual ductal shunting through the two Gianturco coils initially placed. A thorough diagnostic evaluation, and the gratifying response to the second (successful) coil occlusion procedure rule out other possible causes for this patient's hemolytic process. Our experience represents the first reported case of significant hemolysis following coil occlusion of a patent ductus. Therefore, appearance of anemia in a previously healthy child recently treated with coil embolization of patent ductus arteriosus should be taken seriously, however repeat coil embolization of residual shunts can eliminate ongoing hemolysis and lead to prompt recovery of normal hemoglobin levels.

\section{REFERENCES}

1. Lloyd TR, Fedderly R, Mendelsohn AM, Sandhu SK, Beekman RH: Transcatheter coil occlusion of patent ductus arteriosus with Gianturco coils. Circulation 88:1412-1420, 1993.

2. Lloyd TR, Beekman RH, Moore JW, Hellenbrand WE, Hijazi ZM, Sommer RJ, Zamora R, Rothman A for the PDA coil investigators: The PDA coil registry: 250 patient-years of followup. J Am Coll Cardiol 27 (supplement A):34A, 1996.

3. Shim D, Fedderly RT, Beekman RH, Ludomirsky A, Young ML, Schork MA, Lloyd TR: Follow-up of coil occlusion of patent ductus arteriosus. J Am Coll Cardiol 28:207-211, 1996.

4. Grifka RG, O'Laughlin MP, Mullins CE: Late transcatheter removal of a Rashkind PDA occlusion device for persistent hemolysis using a modified transseptal sheath. Cath and CV Dg 25: 140-143, 1992.

5. Qereshi SA, Huggon IC: Hemolysis associated with umbrella occlusion of the arterial duct (letter). Pediatr Cardiol 16(2):101$102,1995$. 